\title{
Atividade Alelopática em Folhas de Tachigali myrmecophyla (LEG. - PAP.) ${ }^{1}$
}

\author{
Allelopathic Activity in Tachigali myrmecophyla (Leg. - Pap.) Leaves
}

SOUZA FILHO, A.P.S. ${ }^{2}$, LÔBO, L.T. ${ }^{3}$ e ARRUDA, M.S.P. ${ }^{3}$

\begin{abstract}
RESUMO - O uso de espécies florestais com atividade alelopática pode assegurar aos sistemas agroflorestais maior estabilidade, notadamente em relação à redução das espécies de plantas daninhas. Os objetivos deste trabalho foram isolar e identificar substâncias químicas produzidas pelo Tachigali myrmecophyla (tachi-preto) e caracterizar a atividade alelopática sobre a germinação de sementes e o crescimento de plântulas de duas espécies de plantas daninhas. Os bioensaios foram realizados em condições controladas de $25^{\circ} \mathrm{C}$ e fotoperíodos de 12 horas para germinação e de $25{ }^{\circ} \mathrm{C}$ e fotoperíodo de 24 horas para o desenvolvimento de radícula e hipocótilo. Os extratos brutos e as frações foram analisados em concentração de 1,0 e 0,5\%, e a substância, em concentrações de $5,10,15$ e $20 \mathrm{mg} \mathrm{L}^{-1}$. O processo de isolamento permitiu a identificação da substância química 4,5-diidroblumenol A. Essa substância evidenciou atividade alelopática, cujos efeitos variaram em função da concentração, da espécie de planta daninha e do parâmetro da planta analisado. A intensidade dos efeitos alelopáticos esteve positivamente associada à concentração, com os efeitos mais intensos observados na concentração de $20 \mathrm{mg} \mathrm{L}^{-1}$. Independentemente do parâmetro analisado, os efeitos foram de maior magnitude na planta malícia. Comparativamente, o desenvolvimento da radícula se mostrou mais sensivel aos efeitos da substância que o desenvolvimento do hipocótilo e a germinação das sementes.
\end{abstract}

Palavras-chave: alelopatia, inibição, germinação, crescimento.

\begin{abstract}
The use of forest species with allelopathic activity can promote a higher stability to agroforestry systems, mainly relative to the reduction of weed species. The objective of this study was to isolate and identify chemical substances produced by Tachigali myrmecophyla and characterize its inhibitory allelopathic activity on the germination and seedling development of two weed species. Bioassays were carried out under controlled conditions of $25{ }^{\circ} \mathrm{C}$ and 12-hour photoperiod for germination and 24-hour photoperiod for radicle and hypocotyl development. The extracts and fractions were analyzed under concentrations of $1.0 \%$ and $0.5 \%$, and the substance under concentrations of $5,10,15$ and $20 \mathrm{ppm}$. The isolation process allowed the identification of the chemical substance 4,5-dihydroblumenol A. This substance showed allelopathic activity, with the effects varying according to concentration, weed species and the plant parameter analyzed. The intensity of the allelopathic effects was positively associated to the concentration. Mimosa pudica was the most affected weed species. Radicle development was more sensitive plant to the substance effects than hypocotyl development and seedling germination.
\end{abstract}

Key words: allelopathy, inhibition, germination, development.

Recebido para publicação em 28/2/2005 e na forma revisada em 25/11/2005.

2 Embrapa Amazônia Oriental, Trav. Dr. Enéas Pinheiro, S/N. 66095-100 Belém-PA. ${ }^{3}$ Universidade Federal do Pará, Rua Augusto Corrêa 01, 66075-900 Belém-PA. 


\section{INTRODUÇÃO}

Em áreas tropicais, onde predominam solos de baixa fertilidade e acidez elevada, há crescente interesse pelos sistemas agroflorestais como alternativa para a exploração agrícola. Esses sistemas agrícolas têm se mostrado mais equilibrados, do ponto de vista ambiental e da sustentabilidade, que aqueles baseados no monocultivo, tradicionalmente utilizados.

Nos sistemas agroflorestais, a utilização de espécies arbóreas com características apropriadas - a exemplo da fixação do nitrogênio pelas leguminosas - é fundamental para a estabilidade e o sucesso do sistema. Aspectos relativos à melhoria do conforto animal, proporcionado pelo sombreamento, e da paisagem são pontos extremamente positivos, representando ganhos substanciais. Paralelamente, espécies arbóreas, em especial da família das leguminosas, com atividade alelopática podem desempenhar papel crucial na estabilidade dos sistemas agroflorestais, em especial pela possibilidade de exercer controle da infestação das plantas daninhas, notadamente em áreas de pastagens cultivadas (Souza Filho \& Alves, 1998).

Em razão de sua rica biodiversidade de plantas, a Região Amazônica pode contribuir não só com o fornecimento de novas e importantes espécies arbóreas com propriedades desejáveis para compor sistemas agroflorestais estáveis ao longo do tempo, como ainda fornecer novas moléculas químicas com possibilidade de uso na agricultura. Como exemplo desses aspectos, vários trabalhos foram desenvolvidos nos últimos anos envolvendo a prospecção de substâncias químicas com atividade alelopática em espécies arbóreas (Souza Filho \& Alves, 2000; Gonzáles et al., 1995; Borges et al., 1993; Rizvi et al., 1999; Lisanework \& Michelsen, 1993).

O gênero Tachigali tem importante contribuição na formação da floresta amazônica, encontrando-se entre os 15 mais comuns na floresta nacional do Tapajós, em Santarém (Guimarães \& Pyler, 1999). Algumas espécies desse gênero têm sido estudadas: T. Alba, T. multifuga, T. versicolor; T. Paniculata e T. myrmecophyla (Goi et al., 1984; Parker, 2000; Cioffi et al., 2002). À semelhança das demais espécies, Tachigali myrmecophyla (tachi-preto) tem sido pouco explorada pelos produtores, eventualmente para a produção de carvão; entretanto, devido ao seu crescimento rápido e à capacidade de fixação de nitrogênio, possui potencial para ser adotada na formação de sistemas agroflorestais.

As fontes disponiveis para agentes alelopáticos podem ser ordenadas em três grupos: a) metabólitos secundários originários de espécies pertencentes a um mesmo ecossistema estudado; b) metabólitos originários de outros ecossistemas não necessariamente relacionados com um determinado estudo; e c) síntese similar de aleloquímicos (Macias, 1995). Considerando-se que o tachi-preto é uma espécie arbórea nativa da floresta amazônica e que ainda não foi utilizada em sistemas agroflorestais, este estudo se insere na estratégia "b" .

Os objetivos desta pesquisa foram isolar e identificar substâncias químicas produzidas pelo Tachigali myrmecophyla (tachi-preto) e caracterizar a atividade alelopática sobre a germinação de sementes e o desenvolvimento de plântulas de duas espécies de plantas daninhas.

\section{MATERIAL E MÉTODOS}

\section{Coleta e preparo do material vegetativo}

Folhas de plantas de Tachigali myrmecophyla (conhecida popularmente pelo nome de tachipreto) foram coletadas no Campo Experimental da Embrapa Amazônia Oriental, localizado em Belém, PA. Em seguida, o material foi seco em estufa de circulação de ar forçado, por 72 horas, à temperatura de $40{ }^{\circ} \mathrm{C}$, sendo posteriormente triturado em moinho tipo Willey, acondicionado em sacos de plástico e mantido em condições ambientais até utilização. O processo resultou na obtenção de $3,7 \mathrm{~kg}$ de folhas secas e trituradas.

\section{Procedimentos de isolamento e identificação da substância química}

A partir do material seco e moído, realizouse a primeira extração, envolvendo a mistura de metanol e água na proporção de 8:2, sob aquecimento em banho-maria $\left(40^{\circ} \mathrm{C}\right)$, por 
período de oito horas, seguida de filtração e evaporação do metanol, em rotavapor Buchi, modelo EL 131. No extrato resultante desse processo, procedeu-se a nova extração, líquido: líquido, na proporção de $1: 1$, com solvente de polaridade crescente, obedecendo à seguinte ordem de utilização: hexano, diclorometano, acetato de etila. Em seguida, os solventes foram evaporados em rotavapor Buchi, obtendo-se os extratos brutos hexânico (EBHX), diclometânico (EMDM) e acetato de etila (EBAEt). O resíduo líquido desse processo foi liofilizado e utilizado para compor o extrato bruto aquoso (EBAq) (Figura 1).

As técnicas de separação, purificação e identificação da substância com atividade alelopática envolveram os seguintes procedimentos:

1. Cromatografia - a fase estacionária é sólida, utilizando-se sílica-gel 70-230 Mesh (cromatografia de coluna) e sílica-gel GF e PF (cromatografia em placa). A fase móvel é líquida e, nesse caso, são utilizados os solventes hexano, diclorometano, acetato de etila, metanol e água.

2. Coluna Cromatográfica por Via Úmida (CCVU) - foi realizada em coluna de vidro, de diâmetro e altura variando em função da quantidade de amostra. A sílica-gel (fase estacionária) é colocada na coluna após ser misturada ao solvente de escolha prévia. A amostra utilizada é fracionada com misturas de solventes de polaridade crescente (fase móvel).

3. Cromatografia em Camada Delgada Comparativa (CCDC) - utilizaram-se placas de vidro (plana) de $5 \times 10 \mathrm{~cm}$, preparadas com fina camada de sílica-gel 60 GF-Merck, de $0,5 \mathrm{~mm}$ de espessura, para monitoramento do processo de separação dos extratos e das frações.

\section{Fracionamento das diferentes fases -} 1. Diclorometânica - foi fracionada por CCVU filtrante, empregando-se misturas de solventes de polaridade crescente: hexano $100 \%\left(\mathrm{D}_{1}\right)$; hexano/acetato de etila - 30\% $\left(\mathrm{D}_{2}\right)$; hexano/acetato de etila - $50 \%\left(\mathrm{D}_{3}\right)$; acetato de etila - $100 \%\left(\mathrm{D}_{4}\right)$; e acetato de etila/metanol $20 \%\left(D_{5}\right)$ (Figura 1). A fração D1, pelo fato de a massa obtida ser insuficiente, não foi submetida a bioensaio.
A elucidação estrutural foi realizada por ressonância magnética nuclear $\left(\mathrm{RMN}{ }^{1} \mathrm{H}, \mathrm{RMN}\right.$ ${ }^{13} \mathrm{C}$ e DEPT), espectro de COSY e de HECTOR.

\section{Análise da atividade alelopática}

Os efeitos potencialmente alelopáticos dos extratos brutos e das frações foram avaliados sobre a germinação das sementes da planta daninha Mimosa pudica (malícia), enquanto para a substância química isolada e identificada avaliaram-se a germinação de sementes e o desenvolvimento da radícula e do hipocótilo das plantas daninhas malícia e mata-pasto (Senna obtusifolia).

As sementes dessas duas plantas daninhas foram coletadas em áreas de pastagens cultivadas, no município de Castanhal, Estado do Pará. Posteriormente, passaram por processo de limpeza e foram tratadas com ácido sulfúrico, com vistas à superação da dormência, conforme estabelecido por Souza Filho et al. (1998b).

Os bioensaios de germinação foram desenvolvidos em câmara de germinação, em condições controladas de $25{ }^{\circ} \mathrm{C}$ de temperatura constante e fotoperíodo de 12 horas. A germinação foi monitorada em períodos de 15 dias, com contagens diárias e eliminação das sementes germinadas. Consideraram-se sementes germinadas aquelas que apresentavam extensão radicular igual ou superior a 2,0 mm (Duram \& Tortosa, 1985; Juntila, 1976). Foram empregadas, em cada placa de Petri de 9,0 cm de diâmetro, 25 sementes de cada espécie de planta daninha (malícia e mata-pasto) utilizada como receptora.

Os bioensaios de desenvolvimento da radícula e do hipocótilo foram realizados em câmaras de germinação, em condições específicas de $25{ }^{\circ} \mathrm{C}$ de temperatura constante e fotoperíodo de 24 horas. Utilizaram-se três sementes pré-germinadas para cada placa de Petri, sendo, após o período de 10 dias de crescimento, medido o comprimento da radícula e do hipocótilo.

As avaliações dos extratos brutos e das frações foram feitas em concentrações de 1,0 e $0,5 \%$, respectivamente, tendo como eluente os respectivos solventes, de onde o extrato bruto e as frações foram obtidos. Para a substância

Planta Daninha, Viçosa-MG, v. 23, n. 4, p. 557-564, 2005 
isolada, as concentrações foram de 5, 10, 15 e $20 \mathrm{mg} \mathrm{L}^{-1}$, utilizando-se como eluente o metanol. Em todos os bioensaios, foram adicionados, em cada placa de Petri, 3,0 mL de extrato bruto, frações ou substância. Após a evaporação dos solventes, adicionavam-se 3,0 mL de água destilada, mantendo-se, dessa forma, a mesma concentração. Os extratos, as frações e a substância química isolada foram aplicados apenas uma vez, quando do início de cada bioensaio, sendo, a partir de então, adicionada apenas água destilada, sempre que se fazia necessário.

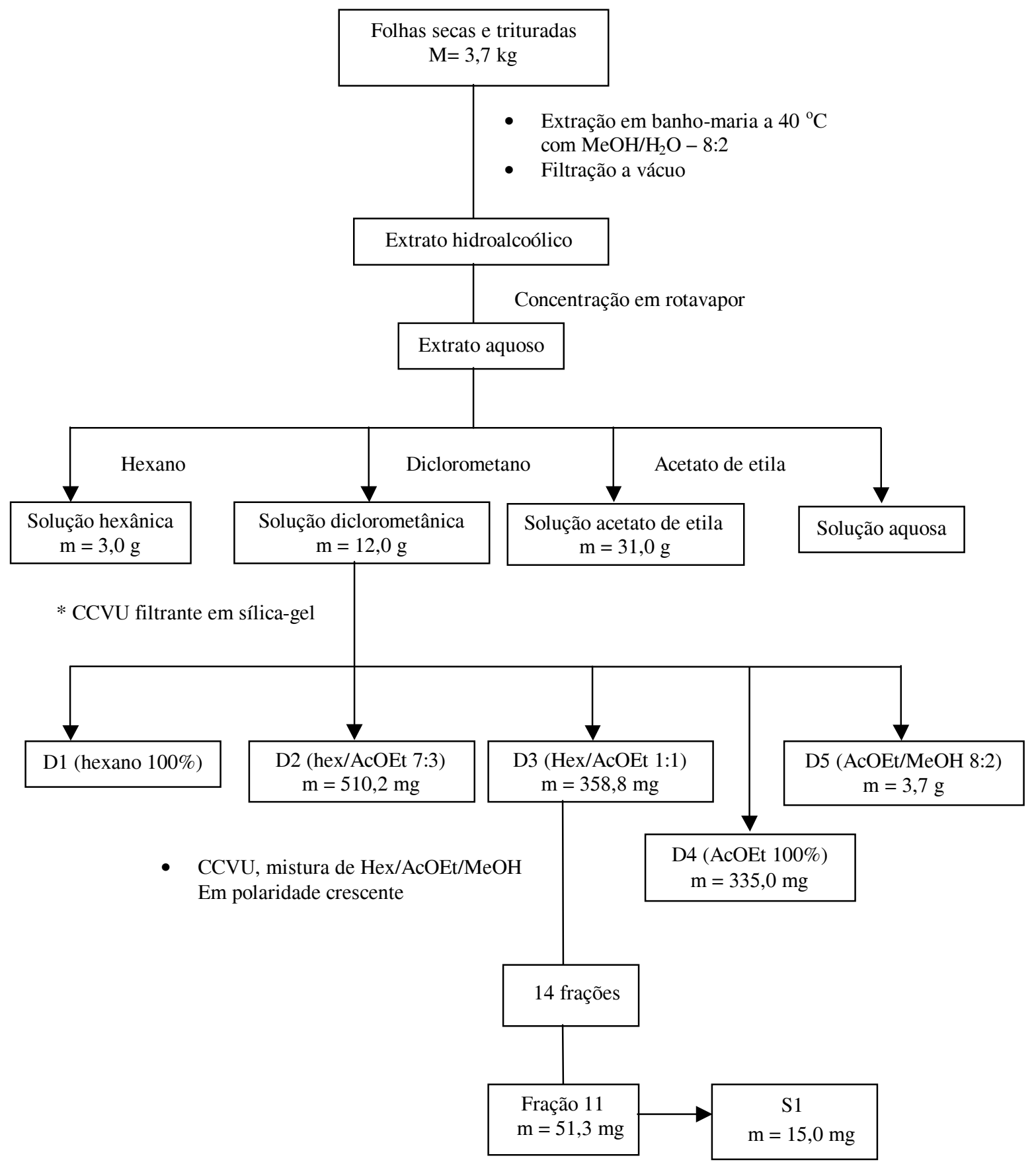

Figura 1 - Procedimentos de isolamento e identificação de substância química com atividade alelopática presente em folhas de tachi-preto. 


\section{Análise estatística}

O delineamento experimental foi inteiramente casualizado, com três repetições. Os dados foram submetidos à análise de variância pelo teste $\mathrm{F}$ e as médias comparadas pelo teste de Tukey (5\%). Na análise desses dados utilizou-se o software SAS (Sas, 1989).

\section{RESULTADOS E DISCUSSÃO}

\section{Identificação de substância química com atividade alelopática}

Na Figura 1 é apresentado, de forma suscinta, os procedimentos que levaram ao isolamento e à identificação da substância com atividade alelopática, na parte aérea do tachi-preto. Cada fase dessa seqüência foi acompanhada de avaliação dos efeitos alelopáticos sobre a germinação das sementes das plantas daninhas malícia e mata-pasto. Comparativamente, as substâncias químicas presentes nos extratos brutos acetato de etila e diclorometano foram as que produziram as maiores inibições sobre a germinação das sementes das duas plantas daninhas (Figura 2). Entretanto, em face da superioridade verificada para os efeitos inibitórios no extrato bruto acetato de etila e considerando que a polaridade dessa fração é maior que a do diclorometano, optou-se pelo fracionamento do acetato de etila.

Do extrato bruto acetato de etila foram obtidas cinco frações da combinação binária, envolvendo hexano/acetato de etila/metanol. A avaliação da atividade alelopática dessas frações indicou que a combinação $(1: 1)$ de hexano/acetato de etila foi a que promoveu inibição mais intensa da germinação das sementes das espécies malícia e mata-pasto: 100 e 35\%, respectivamente (Figura 3). Embora em menor magnitude, a fração acetato de etila $(100 \%)$ também evidenciou alta atividade inibitória; contudo, para efeito de fracionamento, deu-se prioridade ao acetato de etila, pela superioridade apresentada no bioensaio.

Por meio de CCVU, envolvendo a utilização dos solventes hexano/acetato de etila/metanol (ver fluxograma na Figura 1), em combinações binárias com polaridade crescente, foram obtidos 14 frações; destas, utilizando-se novamente CCVU, com misturas de hexano/ acetato de etila/metanol, em combinações binárias, com polaridade crescente, obteve-se a substância $\mathbf{S 1}$.

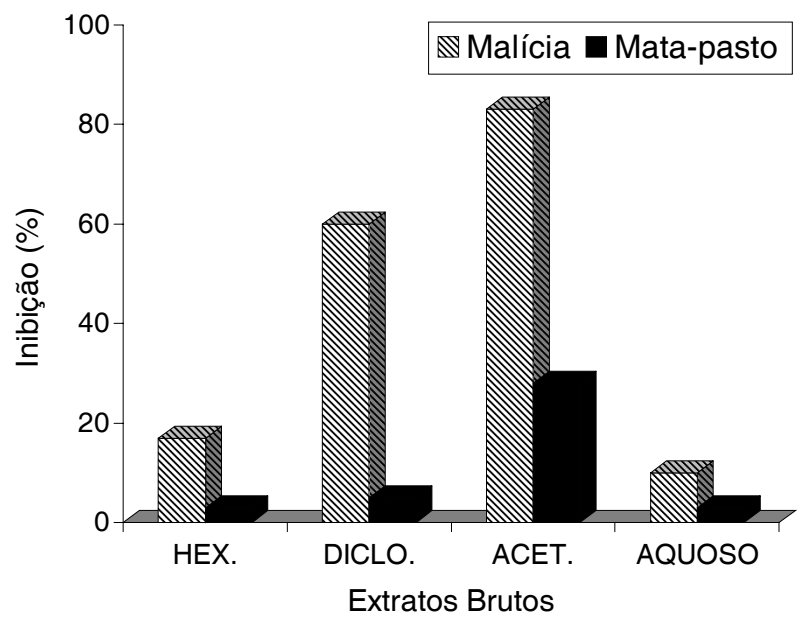

Figura 2 - Efeitos de extratos brutos sobre a germinação de sementes de duas plantas daninhas. HEX. = hexano; DICLO. = diclorometano; ACET. = acetato de etila; AQUOSO = extrato aquoso. Dados expressos em percentual de inibição em relação ao tratamento testemunha (água destilada).

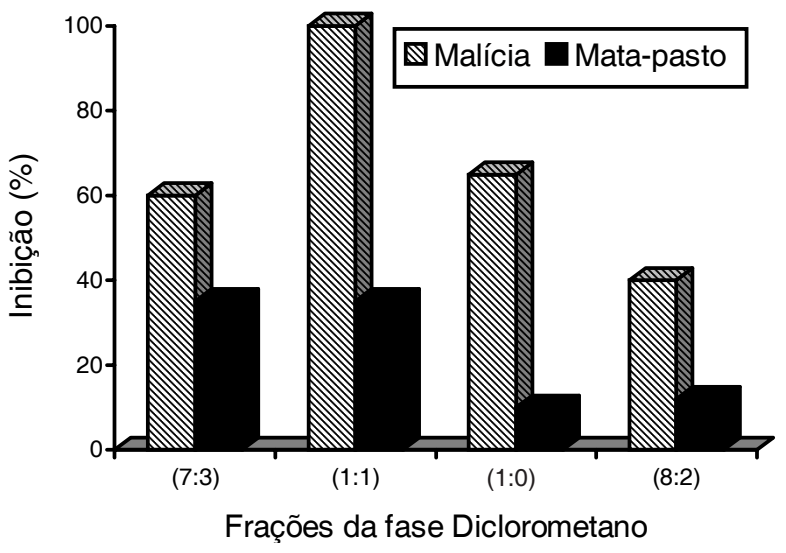

Figura 3 - Efeitos das frações obtidas da fase diclorometano, sobre a germinação de sementes de duas plantas daninhas. $(7: 3)=$ Hex/acetato $(7: 3) ;(1: 1)=$ Hex/acetato $(1: 1) ;(1: 0)=$ acetato $(1: 0) ;(8: 2)=$ acetato/metanol $(8: 2)$.

Pela análise do espectro de $\mathrm{RMN}{ }^{1} \mathrm{H}$ (Tabela 1) de $\mathbf{S 1}$, observaram-se sinais na região de hidrogênios olefínicos, carbinólicos e alifáticos. Os sinais relativos a esses hidrogênios são:

Planta Daninha, Viçosa-MG, v. 23, n. 4, p. 557-564, 2005 
1. Para os hidrogênios olefínicos: dois duplos dupletos em $\delta 5,69(J=15,8$ e $1,0 \mathrm{~Hz})$ e 5,83 $(J=15,8$ e $6,0 \mathrm{~Hz})$, integrando para um hidrogênio cada, indicando ligação $-\mathrm{HC}=\mathrm{CH}-$ com os hidrogênios em relação trans, observada pelos valores de constante de acoplamento $(J=15,8 \mathrm{~Hz})$.

2. Para o hidrogênio carbinólico: um quinteto de dupletos em $\delta 4,43(J=6,5$ e $1,0 \mathrm{~Hz})$.

3. Para os hidrogênios do grupo metila: um sinal dupleto referente a uma metila ligada a $\mathrm{CH}$ em $\delta 1,32(J=6,5 \mathrm{~Hz})$.

Observaram-se ainda dois multipletos em $\delta 2,18$ e 2,39 , cada um integrando um hidrogênio, podendo ser atribuído aos hidrogênios de grupo-CH-CO-, um duplo tripleto em $\delta 2,83$ $(J=13,5$ e $1,0 \mathrm{~Hz})$, um duplo dupleto em $\delta 1,90$ $(J=13,5$ e $2,1 \mathrm{~Hz})$ e um dupleto em $\delta 2,22$.

Os sinais de ${ }^{13} \mathrm{C}$ que caracterizaram a estrutura de $\mathbf{S 1}$ foram: um sinal em $\delta 211,4$, relacionado ao carbono de carbonila em anel cicloexano; dois sinais em $\delta 135,2$ e 131,8, relativos aos dois carbonos $\mathrm{CH}$ olefínicos; um sinal em $\delta 77,2$, atribuído a um carbono oxidado totalmente substituído; um sinal em $\delta 68,7$, assinalado a um carbono oximetínico; quatro sinais referentes a quatro metilas em $\delta 24,5$, $24,4,23,9$ e 15,9; dois sinais de carbonos metilênicos vizinhos à carbonila em $\delta 45,1 \mathrm{e}$ 51,5; um sinal de carbono metínico em $\delta 36,4$; e um sinal de carbono totalmente substituído em $\delta 42,6$.

Tabela 1 - Dados de RMN ${ }^{1} \mathrm{H}$ e ${ }^{13} \mathrm{C}\left(300\right.$ e $\left.75 \mathrm{MHz}, \mathrm{CDCl}_{3}\right)$, para $\mathbf{S 1}$

\begin{tabular}{|c|c|c|}
\hline Posição & ${ }^{1} \mathrm{H}(\mathrm{ppm})$ & ${ }^{13} \mathrm{C}$ \\
\hline 1 & & 42,6 \\
\hline 2 & $\begin{array}{l}2,18 m \\
2,18 m\end{array}$ & 45,1 \\
\hline 3 & & 211,4 \\
\hline 4 & $\begin{array}{l}\text { Heq. } 2,83 d t(\mathrm{~J}=13,5 \text { e } 1,0 \mathrm{~Hz}) \\
\text { Hax. } 1,90 d d(\mathrm{~J}=13,5 \text { e } 2,1 \mathrm{~Hz})\end{array}$ & 51,5 \\
\hline 5 & $2,22 \mathrm{~m}$ & 36,4 \\
\hline 6 & & 77,2 \\
\hline 7 & $5,69 d d(\mathrm{~J}=15,8$ e $1,0 \mathrm{~Hz})$ & 131,8 \\
\hline 8 & $5,83 d d(\mathrm{~J}=15,8$ e $6,0 \mathrm{~Hz})$ & 135,2 \\
\hline 9 & $4,43 q d(\mathrm{~J}=6,5$ e $1,0 \mathrm{~Hz})$ & 68,3 \\
\hline 10 & $1,32 d(\mathrm{~J}=6,5 \mathrm{~Hz})$ & 23,9 \\
\hline 11 & $0,96(s)$ & 24,5 \\
\hline 12 & $0,93(s)$ & 24,4 \\
\hline 13 & $0,87 d(\mathrm{~J}=6,3 \mathrm{~Hz})$ & 15,9 \\
\hline
\end{tabular}

Esses dados permitiram estabelecer a estrutura de $\mathbf{S 1}$ como sendo 4,5-diidroblumenol A, cuja estrutura é apresentada na Figura 4. Essa estrutura está, ainda, em consonância com aquela proposta por Kuo \& Li (1997) e Gonzáles et al. (1994).

\section{Análise da atividade alelopática}

A análise dos efeitos alelopáticos do 4,5diidrobulmenol A sobre os parâmetros analisados indicou variação significativa $(\mathrm{P}<0,05)$ quando se analisaram tanto os efeitos sobre a germinação das sementes (Tabela 2) quanto aqueles sobre o desenvolvimento da radícula (Tabela 3) e do hipocótilo (Tabela 4). Variações observadas na intensidade dos efeitos podem ser creditadas aos fatores concentração da substância e espécie de invasora. A atividade biológica de determinado aleloquímico está associada tanto à concentração como ao limite de resposta da espécie afetada (Reigosa et al., 1999; Abrahim et al., 2000). Neste trabalho, a inibição variou positivamente em função do aumento da concentração da substância, embora esses aumentos não tenham correspondido, em alguns casos, a diferenças significativas.

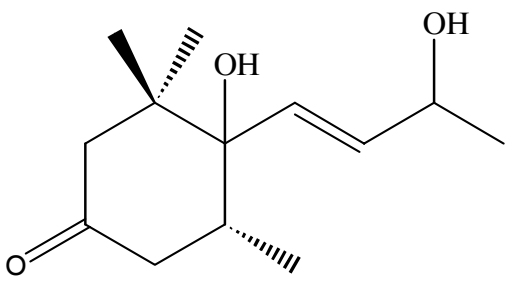

$\mathbf{S}_{1}$

Figura 4 - Estrutura química do 4,5-diidroblumenol A.

Tabela 2 - Efeito de 4,5-diidroblumenol A sobre a germinação de sementes de plantas daninhas. Dados expressos em percentual de inibição em relação ao tratamento testemunha (água destilada)

\begin{tabular}{|l|c|c|c|c|}
\hline \multirow{2}{*}{ Planta Daninha } & \multicolumn{4}{|c|}{ Concentrações $\left(\mathrm{mg} \mathrm{L}^{-1}\right)$} \\
\cline { 2 - 5 } & 5 & 10 & 15 & 20 \\
\hline Malícia & $10 \mathrm{Ac}$ & $12 \mathrm{Ac}$ & $22 \mathrm{Ab}$ & $27 \mathrm{Ba}$ \\
\hline Mata-pasto & $5 \mathrm{Bc}$ & $6 \mathrm{Bc}$ & $15 \mathrm{Bb}$ & $32 \mathrm{Aa}$ \\
\hline
\end{tabular}

Médias seguidas de letras iguais, maiúsculas na coluna e minúsculas na linha, não diferem pelo teste de Tukey (5\%). 
Tabela 3 - Efeito de 4,5-diidroblumenol A sobre o desenvolvimento da radícula de plantas daninhas. Dados expressos em percentual de inibição em relação ao tratamento testemunha (água destilada)

\begin{tabular}{|l|c|c|c|c|}
\hline \multirow{2}{*}{ Planta Daninha } & \multicolumn{4}{|c|}{ Concentrações $\left(\mathrm{mg} \mathrm{L}^{-1}\right)$} \\
\cline { 2 - 5 } & 5 & 10 & 15 & 20 \\
\hline Malícia & $12 \mathrm{Ac}$ & $33 \mathrm{Ab}$ & $80 \mathrm{Aa}$ & $82 \mathrm{Aa}$ \\
\hline Mata-pasto & $5 \mathrm{Bd}$ & $12 \mathrm{Bc}$ & $31 \mathrm{Bb}$ & $52 \mathrm{Ba}$ \\
\hline
\end{tabular}

Médias seguidas de letras iguais, maiúsculas na coluna e minúsculas na linha, não diferem pelo teste de Tukey (5\%).

Tabela 4 - Efeito de 4,5-diidroblumenol A sobre o desenvolvimento do hipocótilo de plantas daninhas. Dados expressos em percentual de inibição em relação ao tratamento testemunha (água destilada)

\begin{tabular}{|l|c|c|c|c|}
\hline \multirow{2}{*}{ Planta Daninha } & \multicolumn{4}{|c|}{ Concentrações $\left(\mathrm{mg} \mathrm{L}^{-1}\right)$} \\
\cline { 2 - 5 } & 5 & 10 & 15 & 20 \\
\hline Malícia & $3 \mathrm{Ab}$ & $4 \mathrm{Ab}$ & $42 \mathrm{Aa}$ & $45 \mathrm{Aa}$ \\
\hline Mata-pasto & $5 \mathrm{Ac}$ & $7 \mathrm{Ac}$ & $13 \mathrm{Bb}$ & $31 \mathrm{Ba}$ \\
\hline
\end{tabular}

Médias seguidas de letras iguais, maiúsculas na coluna e minúsculas na linha, não diferem pelo teste de Tukey (5\%).

O conceito de alelopatia cunhado por Molisch em 1937 (Rice, 1987) envolve tanto os efeitos deletérios como os estimulatórios. Aparentemente, estes últimos estão associados à concentração da substância, manifestando-se em situação de baixa concentração (Rice, 1984). No presente trabalho, mesmo em concentrações tão baixas como $5,0 \mathrm{mg} \mathrm{L}^{-1}$, não foram observados efeitos estimulatórios, e sim inibitórios, tanto sobre a germinação das sementes (Tabela 2) como no crescimento da radícula (Tabela 3) e do hipocótilo (Tabela 4).

Especificamente sobre os efeitos promovidos sobre a germinação das sementes (Tabela 2), as diferenças observadas, em função da espécie receptora, podem ser atribuídas à variação no tamanho das sementes. Souza Filho et al. (2003) mostram que sementes pequenas, como as de malícia, são mais intensamente afetadas do que sementes grandes, como é o caso das sementes de mata-pasto.

A análise comparativa dos efeitos promovidos sobre os diferentes parâmetros das plantas indica variações no grau de inibição promovido pela substância. Em concentrações de 5,0 e 10,0 $\mathrm{mg} \mathrm{L}^{-1}$ a inibição da germinação não ultrapassa $12,0 \%$ (Tabela 2); está sempre abaixo de $8,0 \%$ no crescimento da radícula (Tabela 3); e atinge 33,0\% no crescimento do hipocótilo (Tabela 4). Na concentração mais elevada, 20 ppm, observam-se inibições da ordem de 82,0 e $52,0 \%$ sobre o crescimento da radícula de malícia e mata-pasto. Nesta mesma concentração, inibições de 45,0 e 31\% sobre o crescimento da radícula e de 27,0 e $32,0 \%$ sobre o crescimento do hipocótilo são observadas para malícia e mata-pasto, respectivamente. Esses dados mostram que, independentemente da espécie de planta daninha, o crescimento da radícula foi o parâmetro mais sensivel aos efeitos do 4,5-diidrobulmenol A do que a germinação das sementes ou mesmo o crescimento do hipocótilo.

\section{LITERATURA CITADA}

ABRAHIM, D. et al. Effects of four monoterpenes on germination, primary root growth, and mitochondrial respiration of maize. J. Chem. Ecol., v. 26, n. 2, p. 611-624, 2000.

BORGES, E.E.L.; LOPES, E.S.; SILVA, G.F. Avaliação de substâncias alelopáticas em vegetação de uma floresta secundária. 1- árvore. R. Árvore, v. 17, n. 1, p. 69-84, 1993.

CIOFFI, G. et al. Antioxidant and free-radical scavenging activity of constituents of leaves of Tachigali paniculata. J. Nat. Prod., v. 65, p. 1526-1529, 2002.

DURAM, R. D.; TORTOSA, M. E. The effect of mechanical and chemical scarification on germination of charlock (Sinapsis arvesis L.) seeds. Weed Sci. Technol., v. 13, n. 1, p. 155-163, 1985.

GONZÁLES, L.; SOUTO, X. C.; REIGOSA, M. J. Allelopathic effects of Acacia melanoxylon R. Br. Phyllodes during their decomposition. For. Ecol. Manag., v. 77, n. 1-3, p. 53-63, 1995.

GANZÁLES et al. 4,5-Dihydroblumenol A, a new norisoprenoid from Perrottetia multiflora. J. Nat. Prod., v. 57, n. 3, p. 400-402, 1994.

GOI, S. R.; FARIA, S. M.; NEVES, M. C. Fixação de nitrogênio, tipo de nódulo e ocorrência de ureídos em leguminosas florestais. Pesq. Agropec. Bras., v. 19, p. 185-190, 1984.

Planta Daninha, Viçosa-MG, v. 23, n. 4, p. 557-564, 2005 
GUIMARÃES, E. G. T.; PYLER, E. H. Levantamento florestal de 20 ha na floresta Nacional do Tapajós. Santarém: L.B.A., 1999. 30 p. (Série Ecologia)

JUNTILA, O. Seed and embryo germination in S. vulgaris and $S$, reflexas as affected by temperature during seed development. Physiol. Plant., v. 29, p. 264-268, 1976.

KUO, Y. H.; LI, Y. C. Constituents of bark of Ficus microcarpa L. f. J. Chin. Chem. Soc., v. 44, p. 321-325, 1997.

LISANEWORK, N.; MICHELSEN, A. Allelopathy in agroforestry systems: the effects of leaf extracts of Cupressus lusitania and Eucaliptus spp. on four ethiopian crops. Agrofor. Syst., v. 21, n. 1, p. 63-74, 1993.

MACIAS, F.A. Allelopathy in the search of natural herbicide models. In: DAKISHINI, K. M. M.; EINHELLIG, F. A. (Eds.) Allelopathy: organisms, processes and applications. Washington: American Chemical Society, 1995. p. 310-329. (ACS. Symposium Series, 582).

PARKER, M. A. Divergent Brandyhizobium symbionts on Tachigali versicolor from Barro Colorado Island, Panamá. Syst. Appl. Microbiol., v. 23, p. 585-590, 2000.

REIGOSA, M. J.; SÁNCHEZ-MOREIRA, A.; GONZÁLEZ, L. Ecophysiological approach in allelopathy. Crit. Rev. Plant Sci., v. 18, n. 5, p. 577-608, 1999.
RICE, E.L. Allelopathy: an overview. In: WALLER, G. R. (Ed.) Allelochemical, role in agriculture and forestry. Eashington: American Chemical Society, 1987. p. 7-22.

(ACS. Sympossium Series, 330).

RICE, E. L. Allelopathy. New York: Academic Press, 1984. $422 \mathrm{p}$.

RIZVI, D. J. H. et al. Allelopathy interation in agroforestry systems. Crit. Rev. Plant Sci., v. 18, n. 6, p. 773-796, 1999.

SAS-INSTITUTE. Statistical Analysis System. User's guide. Version 6. 4.ed. Cary: 1989. 846 p.

SOUZA FILHO, A. P. S.; ALVES, S. M.; FIGUEIREDO, F. J. C. Efeitos alelopáticos do calopogônio em função de sua idade e da densidade de sementes da planta receptora. Planta Daninha, v. 21, n. 2, p. 211-218, 2003.

SOUZA FILHO, A. P. S.; ALVES, S. M. Potencial alelopatico de plantas de acapu (Vouacapoua americana): efeitos sobre plantas daninhas de pastagens. Planta Daninha, v. 18, n. 3, p. 435-441, 2000.

SOUZA FILHO, A. P. S.; ALVES, S. M. Alelopatia em ecossistema de pastagem cultivada. Belém: Embrapa Cpatu, 1998. 72 p. (Embrapa - Cpatu. Documentos, 109).

SOUZA FILHO, A. P. S.; DUTRA, S.; SILVA, M. A. M. M. Métodos de superação da dormência de sementes de plantas daninhas de pastagens cultivadas da Amazônia. Planta Daninha, v. 16, n. 1, p. 3-11, 1998. 